\title{
TeMPS: A Conceptual Framework for Pervasive and Social Games
}

\author{
Hong Guo/ Hallvard Trætteberg/ Alf Inge Wang/ Meng Zhu \\ Department of Computer and Information Science \\ Norwegian University of Science and Technology \\ Trondheim, Norway \\ Email: \{guohong, hal, alfw, zhumeng\}@idi.ntnu.no
}

\begin{abstract}
Pervasive and social game is an emerging game genre which brings more physical movement and social interactions into game. This article proposes the conceptual framework TeMPS that systematically characterize the important aspects of pervasive and social games. Further, around thirty games in different sub-genres are reviewed by analyzing and fitting them into the framework. The framework is helpful for game designers to understand and communicate about such games. Further, it contributes to conceptual modeling of pervasive and social games, and to the construction of a game modeling tool
\end{abstract}

Keywords-game review; pervasive game; social game; conceptual framework;

\section{INTRODUCTION}

During recent years, there is a growing trend that can be referred to as pervasive and social games, which brings more physical movement and social interactions into game world.

Examples of such games are "Mobio Threat [1]", "The Drop [2]", "SupaFly [3]", "Epidemic Menace [4]", and "Capture the Flag [5]". According to the dictionary, the word pervasive has a clear meaning. It is an adjective indicating (the quality of) any given object or concept to spread, diffuse, or go through something. However, the actual definition of pervasive game is very complex and ambiguous. There are a lot of games that are "pervasive" in different ways [6]:

- A game that depends primarily on pervasive technology and nonstandard input devices;

- A game with a persistent presence in the real world and thus available to the players at all times;

- An existing game that is augmented by computers, resulting in a blend of the real and virtual worlds;

- $\quad$...

Sub-genres mentioned in [7] also reveal the complexity of "pervasive":

- Smart Toy: Toy that senses status and give feedback through connected PC;

- Affective Gaming: Game using human's emotions as direct input;

- Augmented TableTop Games: Traditional tabletop game with fancy effects given by advanced computing techniques;

- Location Aware Games: Mobile Game where the gamers need to physically move;
- Augmented Reality Games: Variant of VR that mixes the virtual image with players' sight.

Some earlier research suggested that "pervasiveness" occurs in different perspectives and levels of intensity, and we need to be aware of the context and the perspectives, while let go of the notion of coining the ultimate definition [6]. Thus instead of defining "what is a pervasive game", we propose a framework that includes the most important characteristics for a game to be pervasive, aiming at answering the questions "why the game is pervasive" and "how pervasive the game is". Although there is some related work which I will talk about later, we have not found similar detailed conceptual framework yet.

The rest of this article is organized as follows: Section 2 describes the TeMPS framework, as well as detailed perspectives and aspects with modern and typical pervasive games as examples; Section 3 reviews around 30 pervasive and social games by analyzing and fitting them in our TeMPS framework; Section 4 talks about some related work; Finally, Section 5 concludes this article and presents directions for further work.

\section{TEMPS - A PERVASIVE AND SOCIAL GAME FRAMEWORK}

To develop the framework, we reviewed literatures about more than 30 pervasive and social games in different subgenres. We identified that those games differ with other traditional computer games in four ways: 'where' the game is played, 'when' the game is played, 'how' the game is played, and 'who' the game is played by. These seemed cover all the possibilities well, but were obviously too rough. We then listed detailed items under these four categories and analyzed games with them. For each pervasive and social game, we checked: 1 , whether these items are precise and enough to differentiate it from other computer games; 2, whether these items are precise and enough to differentiate it from other kinds of pervasive and social games. When either of above failed, we analyzed the reason, revised the items, and reviewed games using new items. After several iterations and final arrangement, we come up with current framework which serves well for all the games we reviewed now. Since these games are selected in different fields and sub-genres, it seems reasonable to say that the framework could work for larger scope also.

The framework is named as 'TeMPS' according to the four perspectives it consists of: 
- Temporality: addressing the temporal property about the game, i.e. the game is played in fixed time/round or not (open beginning and/or open ended);

- Mobility: addressing the spatial property whether the game could be played anywhere or fixed in one place;

- Perceptibility: addressing how the game is mixed with the reality, e.g. does the game construct the appearance of the player proxy in game by sensing the player's real world appearance? Does the player need to physically move to move virtually in game?; finally

- Sociality: addressing the player's relationship and social influence of the game.

In [7], it is said that "Pervasive games are no longer confined to the virtual domain of the computer, but integrate the physical and social aspects of the real world". Our proposed four perspectives collaborate to maximize this integration of real world and game world: Perceptibility enables different means to integrate physical aspects of the real world - the player can physically play the game (jump, run, speak...) as he/she plays in the real world and feel the game world (see, hear, touch...) in similar way as he/she feels the physical world. Sociality integrates social aspects of the real world - the player can play with real human beings in usual way that he/she interacts with them in the real world. Mobility and Temporality extend this integration in spatial and temporal dimensions - in everywhere and during all the time.

Each of the perspectives includes one or more aspects. We will present each of them in turn and exemplify with selected games. How all these selected games fit into our TeMPS framework is presented in Figure 1 in Section 3.

\section{A. Temporality}

We propose two options here. Fixed time/rounds, and Open ended meaning player could play or exit at any time.

Fixed time and fixed rounds are combined because they provide similar feeling from the temporal angle. Commonly, when this is the case, the player focuses on a clear goal and has a strong desire to achieve it before the game ends. During this time, the player is immersive but all that he/she does is gaming (not part of ordinary life).

This is common for competitive game like Brainball [9], ARQuake [10], and etc. On the other hand, if a game is openended, the rhythm slows down, and often, the game weaves with everyday life or even becomes part of everyday life -when one begins a walking journey, he/she may at the same time play Ere Be Dragons [11]. In such cases, you hardly distinguish the virtual world from the real world (The action of walking is both part of the player's everyday life and part of the game input). Besides, in this kind of game, the player's emotions are often naturally (directly or indirectly) introduced into the game, which further blurs the real-virtual borderline. SupaFly [3] is an example of such a game which is more like a community-based virtual soap opera.

Although some games are designed to be open-ended, due to technical or economic reasons, there is an ending ultimately. We will neglect this issue when we review the games later in this paper.

\section{B. Mobility}

Three options are available for the Mobility characteristics.

- Games are played Fixed in one place as most traditional computer games are;

- Games can be played in large-scale outdoor places Anywhere (often also played in everyday life); or

- Games can be played where the player must Move in one place and need physical actions to change gesture, posture, and etc due to requirements of gameplay.

Smart toy (Zowie Playsets [7]) and Tabletop games (Story Toy [7]) are mostly played in a fixed place.

The player is requested to move in all location-based games like Can You See Me Now [12] and Uncle Roy All Around You [7]. Further, players may also need to move due to indirect requirements, such as to collect some objects (Camelot [13] and Treasure [14]), or to snapshot somebody (DARE! [15]).

Movement in one place usually is because the player's posture, motion and similar are sensed and used in the game. QuaGauntlet [7] is a good example, in which, the players need to change their postures to aim, fire, and activate their shields.

\section{Perceptibility}

Perceptibility can be discussed in two ways: 1) how the game percepts the reality, and 2) how the reality (perceived reality of the player) is influenced by the game (reality does not spontaneously percept the game), or how the virtual world is perceived (by player) physically. There have been a lot of ways for computers to know the player's status (motion, location, emotion...) or context (weather, what is seen, what is heard, object/person around) by various sensors (including commonly used camera and microphone) or other means. However, a limitation of the current technologies is that while physical objects may affect virtual objects, it is more difficult to affect physical objects with virtual ones [7]. Apart from traditional methods that provide visual and audio effects, there are some other methods adopted by modern games which gives force/tactile feedback or even move objects. The utilization of these techniques commonly makes games easier to learn, and more engaging.

We will present some currently available aspects from these two ways later. We call these aspects instead of options because they are not exclusive to each other. Instead, they can be used in one game simultaneously.

It is noticeable that there is no certain relationship between a device and what is used in the game through this device. For instance, camera is commonly used to capture the sight, but with advanced computing techniques, it can also be used to capture the motion. On the other hand, to detect motion, you can use either a camera, or an acceleration detector.

1) How game percepts the reality 
Unlike generic input devices which lock people's hands and arms in relatively similar hand postures and spatial location, pervasive games often utilize advanced input devices which enable and encourage players to play in a more natural way.

a) Sight: What the player sees, as in BREAKOUT FOR $T W O$ [16], players in distance see each other by camera and a projector. Sight is more widely used in Augmented Reality Games through head-wearable cameras.

b) Gaze: Indicates where player points or gazes at. This is typically used to shoot at somebody or change camera orientation (Swordplay [17]) in game and etc.

c) Speech, Sound: Use a microphone to capture sound/voice around/from the player. Be aware that these inputs should be used as direct input of game, not purely as a communication channel between players. In Tabletop WarcraftIII [18], meaningful speech is mapped to command primitives provided by the system, like saying "unit one" and "build farm" will result a command to unit one of building farm.

d) Emotion/ HeartRate/ Physiological signal: This is a fascinating way of perceiving input from the user. The player could play by simply thinking hard (Brainball [9]) or trying best to relax (Relax to Win [19]), or when you actually laughs, the game proxy does the same (AffQuake [7]). Further, Ere Be Dragons [11] is played when the player walks to work. The game detects the player's heart rate and creates artistic effects according to it.

e) (Hand/Body) Gesture/Posture, Motion, Balance, Acceleration of Motion: Sense and use player's gesture, posture (AquaGauntlet [7], Control Freaks [20]), motion/acceleration (Swordplay [17]), balance status (TiltPad Pacman [21]), and similar to enable the game proxy to act accordingly. Motion and acceleration sometimes is hard to distinguish, because they often occur at the same time. This is one of the reasons why motion is often detected/ calculated by accelerator sensor /accelerometer also.

f) Location/Route: The player's (or an object's) physical location is used to locate game proxy in the virtual map. This information could be further used to produce meaningful artifacts or image in the virtual world correspondingly. For instance, in Ere Be Dragons [11], a hill is presented when the player passes a bus stop.

Commonly position information is obtained by means of GPS. However, in some games, location is reported by onstreet gamers to online gamers (then manually change the agent's position in virtual street) using mobile phone. We still regard this game as location-based because the game rules require that the gamer physically moves to the place before he/she could report. We consider that this is due to technical constraints or implementation trick (to save money for instance), although commonly, pervasive games sense the players' context automatically instead of manually.

Route is a variant of Location, meaning the route player/object moves along is used in the game by continuously sensing the physical location and calculating afterwards. Your way Your Missions [22] provides an example of this. g) Object sharing: It is tricky to share an object between game and the reality. Common ways are using RFID technique, while easier ways are like what is used in Uncle Roy All Around You [23], in which, online players share some information ("to find a man in red" or "to find the man in the street corner" for instance) with street players, therefore involve objects or persons in the physical world in an indirect way.

Compared with coins in Treasure [14], which serves purely as shared objects, a racket in PingPongPlus [7] serves as a detector at the same time.

Mona Lisa Bookshelf [24] is a very special case of object shared between the reality and the game. In this application, a physical-existed bookshelf is monitored and virtual effect is presented according to its status. What is special is that the shared bookshelf is the only medium through which the application receives input, and the application does not even care who changes the bookshelf status or when and how the status is changed.

It is noticeable that shared object differs with the mediated sight. In the latter, although physical objects exist in the game world also, they are treated purely as an image instead of individual objects. Thus, we do not regard them as shared objects.

\section{2) How the reality is influenced by the game}

Sometimes, the reality is not influenced by the game at all. Like Camelot [13], where an independent virtual world does not exist, the computing technique is purely used as a utility of traditional game. However, we admit that this is debatable since we can regard the virtual game overlaps with the physical game, and that they share the common game entities as well as the common game play and the common...Anyway, in most cases, it is not as difficult as it is to identify the game and the reality, and we are able to identify how the reality is influenced easily.

a) Visual Effect: Show video, image, text which players can sense with their eyes.

The impact on the player is highly decided by the display device, say, head-mounted displays (HMD) (as used in Human Pacman [25]) that possibly brings more shocking feeling because it is all that the player can see. A surround screen VR system (Swordplay [17]) presents things in more natural way than small $2 \mathrm{~d}$ display on a device like PDA.

Visual Effects are usually accompanied by Auditory Effects. However, there are exceptions like Virtual Aquarium and Mona Lisa Bookshelf [24].

b) Blended Visual Effect: Blended Visual Effects are commonly used in AR games in which the gamers see the mixture of actual vision and virtual objects. Head-mounted displays together with a camera and hand-held devices are most commonly used techniques to display such blended visual effect.

c) Auditory Effect: This is related to background music, sound effect etc. Similar with the Visual Effect, the impressions brought differ between different devices. Further, pure auditory effects (without Visual Effect) are often utilized in low-cost game environments like Story Toy [26]. 
d) Tactile/Force Effect: This is typically force feedback as commonly used in console games. However, it is not found in the games reviewed in this paper.

e) Move Objects and Others: This aspect needs to utilize some sort of smart machine to manipulate objects physically according to computer programs. Only one game, Brainball [9], we reviewed has this feature. There are other ways for a game to affect the reality. For instance, although many information systems like online exam systems are not physical, they are part of the real world. When a game affects such information systems, the reality is affected. This is not found in the games we reviewed however.

\section{Sociality}

Sociality is reflected in two aspects.

\section{1) Player Relationship}

Address the relationship between players, or say, what kind of social relationship can be felt between the players. Four options are proposed. Individually - the player does not feel the existence of others in the virtual world when he/she plays the game. Simple Collaborative/Competitive/Opposed relationship is widely used in short duration games bringing a clear but comparatively simple social air: friendly or hostile and etc. Combined (Team Competitive like Mobile Threat [1]) uses several of the above and makes players' relationship a bit more complicated.

Community is the most natural way of experiencing other players' existence and interacting with other players. In such games like DARE! [15], players are commonly allowed to change their role and relationship between each other in an easy and flexible way. Free relationship, further extends the flexibility - meaning the players could change their roles even to audience or non-players, or vice versa [40]. Openended games may be an example, because they often stay dormant for long time (no active player), but alert the player into playing them at a given moment or comes to life when somebody (who becomes the player meanwhile) awakes it in some way.

The player relationships often reflect the game scalability. Few games involve simple relationships among hundreds of players or vice versa -- builds a virtual community with less than 10 players.

\section{2) Social Influence}

Apart from Pure Entertainment as most traditional games provide, more applications use interesting game elements but aim at other goals and bring more social influence, like: Education/ Learning/ Training (Camelot [13] to train children to collaborate), Health Improvement (Ere Be Dragons [11] to monitor players' health status while walking), Personal management (Virtual Aquarium [24] to help building good tooth-brushing habit), and etc.

\section{GAME REVIEW}

The pervasive games have been selected in different subgenres according to [7], and reviewed by characterizing them according to our framework:

- "Smart Toys": (Zowie Playsets [27], Story Toy [26]),
- “Affective Gaming”: (Brainball [9], AffQuake [7], Relax to Win [19]),

- "Augmented Tabletop Games": (STARTS [7], Treasure [14]),

- "Location-based Games": (Can You See Me Now [28], Uncle Roy All Around You [23], Human Pacman [25], The Drop [2], Capture the Flag [5], Epidemic Menace [4], SupaFly [3], The Songs of North [29], Insectopia [30], PAC LAN [31]...),

- "Augmented Reality Games": (AR ${ }^{2}$ Hockey [7], PingPongPlus [32], AquaGauntlet [7], ARQuake [10], ARTankwar [7], Magic Land [33], Tilt-Pad Pacman [21] and etc), and

- Others: like Swordplay [17], NEAT-o-Race [34], Virtual Aquarium [24], Mona Lisa Bookshelf [24], Swordplay [35], Human Trials [36], and Control Freaks [20].

Apart from these kinds of games, we also include several applications which may even hardly be called computer games like Camelot [13] and Ere Be Dragons [11]. Since these applications are typical in some characteristics, it should be helpful to both understanding the framework and exploring game design hints by reviewing them.

Since pervasive games can be classified as an emerging game genre which usually utilizes some high-tech devices or services, there are big possibilities that the games are constrained by technical factors when it is deployed (for instance, location-aware game may not work well in some place where the GPS signal used is not available). We will mainly consider what a game is designed to be instead of the actual working implementation.

When we review the games, instead of a simple classification to different categories, a score is proposed for each game. The games that get higher scores are regarded as somewhat more "pervasive" because they utilize more means to make the player feels "immersive". Although this model of evaluating the "pervasiveness" is not very accurate, it gives some strong indications. We propose the score according to below criteria:

- For each game, all the aspects of Temporality, Mobility, Perceptibility and Sociality are considered and scored individually, and the sum is given as the final score of the game;

- For Temporality, 1 is given to the game if it is Open ended, 0 is given otherwise;

- For Mobility, 1 is given if the game could be played in Anywhere, 0 is given if the game is played in Fixed place, 0.5 is given if the game is played in one place, but requires player to Move physically;

- For Perceptibility, which is considered to be more influential than other perspectives (although a bit subjective), totally 2 is shared by all the aspects involved, and 1 for aspects in each category. Thus, for each aspect about how the game percepts the reality, 0.1 is given if the game utilizes corresponding technique; For each aspect about how the reality is influenced by the reality, 0.25 is given if the game utilizes corresponding technique; 
- For Sociality,

- Player relationship aspect, 1 is given if the game allows free or community relationship between players, 0 is given if the game is played by individuals only, 0.3 is given if the game allows simple player relationship like collaborative or competitive and etc, 0.6 is given if the game allows more complex player relationship like group competitive,

- Social Influence aspect, 1 is given if the game provides non-entertainment influence, 0 is given if the game is purely for entertainment.

\begin{tabular}{|c|c|c|c|c|c|c|c|c|c|c|c|c|c|c|c|c|c|c|}
\hline \multirow[b]{2}{*}{ Score } & \multirow[b]{2}{*}{ Game } & \multirow[b]{2}{*}{ Temp } & \multirow[b]{2}{*}{ Mobili } & \multicolumn{13}{|c|}{ Perceptibility } & \multicolumn{2}{|c|}{ Sociality } \\
\hline & & & & i Sight & t Gaze & Speed & Emot & t Gestu & Motio & o Balan & Loca & Route & Obj & Visual & I Blend & Audic MoveObj & j Relati & i Non-Ent \\
\hline 1.6 & Zowie Playsets & 1 & 0 & & & & & & & & & & 0.1 & 0.25 & & 0.25 & 0 & 0 \\
\hline 1.35 & Story Toy & 1 & 0 & & & & & & & & & & 0.1 & & & 0.25 & 0 & 0 \\
\hline 0.65 & Brainball & 0 & 0 & & & & 0.1 & & & & & & & & & 0.25 & 0.3 & 0 \\
\hline 1.2 & AffQuake, & 0 & 0 & & & & 0.1 & & & & & & & 0.25 & & 0.25 & 0.6 & 0 \\
\hline 0.9 & Relax To Win & 0 & 0 & & & & 0.1 & & & & & & & 0.25 & & 0.25 & 0.3 & 0 \\
\hline 1.25 & STARS & 0 & 0 & & & & & & 0.1 & & & & 0.1 & 0.25 & 0.25 & 0.25 & 0.3 & 0 \\
\hline 2.9 & Treasure. & 1 & 1 & & & & & & & & 0.1 & & & 0.25 & & 0.25 & 0.3 & 0 \\
\hline 2.2 & Can You See Me Now & 0 & 1 & & & & & & & & 0.1 & & & 0.25 & & 0.25 & 0.6 & 0 \\
\hline 1.8 & Uncle Roy All Around You & 0 & 0.5 & & & & & & & & 0.1 & & 0.1 & 0.25 & & 0.25 & 0.6 & 0 \\
\hline 1.85 & $\mathrm{AR}^{2}$ Hockey & 0 & 0.5 & 0.1 & & & & & 0.1 & & & & 0.1 & 0.25 & 0.25 & 0.25 & 0.3 & 0 \\
\hline 1.85 & PingPongPlus & 0 & 0.5 & 0.1 & & & & & 0.1 & & & & 0.1 & 0.25 & 0.25 & 0.25 & 0.3 & 0 \\
\hline 1.45 & AquaGauntlet & 0 & 0.5 & 0.1 & & & & 0.1 & & & & & & 0.25 & 0.25 & 0.25 & 0 & 0 \\
\hline 2.35 & ARQuake & 0 & 1 & 0.1 & & & & & 0.1 & & & & 0.1 & 0.25 & 0.25 & 0.25 & 0.3 & 0 \\
\hline 2.45 & Human Pacman & 0 & 1 & 0.1 & & & & & 0.1 & & 0.1 & & 0.1 & 0.25 & 0.25 & 0.25 & 0.3 & 0 \\
\hline 1.95 & Tilt-Pad Pacman & 0 & 0.5 & 0.1 & & & & & 0.1 & 0.1 & & & 0.1 & 0.25 & 0.25 & 0.25 & 0.3 & 0 \\
\hline 0.95 & Magic Land & 0 & 0 & 0.1 & & & & & & & & & 0.1 & 0.25 & 0.25 & 50.25 & 0 & 0 \\
\hline 1.35 & AR Tankwar & 0 & 0 & 0.1 & 0.1 & & & & & & & & 0.1 & 0.25 & 0.25 & 0.25 & 0.3 & 0 \\
\hline 2.3 & The Drop & 0 & 1 & & & & & & & & 0.1 & & 0.1 & 0.25 & & 0.25 & 0.6 & 0 \\
\hline 2.1 & Mobile Threat & 0 & 1 & & & & & & & & & & & 0.25 & & 0.25 & 0.6 & 0 \\
\hline 2.3 & Capture the Flag & 0 & 1 & & & & & & & & 0.1 & & 0.1 & 0.25 & & 0.25 & 0.6 & 0 \\
\hline 2.4 & Epidemic Menace & 0 & 1 & & & & & & 0.1 & & 0.1 & & 0.1 & 0.25 & & 0.25 & 0.6 & 0 \\
\hline 3.7 & SupaFly & 1 & 1 & & & & & & & & 0.1 & & 0.1 & 0.25 & & 0.25 & 1 & 0 \\
\hline 1.6 & The Songs of North & 0 & 1 & & & & & & & & 0.1 & & & 0.25 & & 0.25 & 0 & 0 \\
\hline 2.4 & Control Freaks & 1 & 0.5 & & & & & & 0.1 & & & & & 0.25 & & 0.25 & 0.3 & 0 \\
\hline 3.7 & Ere Be Dragons & 1 & 1 & & & & 0.1 & & & & 0.1 & & & 0.25 & & 0.25 & 0 & 1 \\
\hline 3.2 & Camelot & 1 & 0.5 & & & & & & & & & & 0.1 & & & & 0.6 & 1 \\
\hline 3.7 & Insectopia & 1 & 1 & & & & & & & & 0.1 & & 0.1 & 0.25 & & 0.25 & 1 & 0 \\
\hline 3.6 & DARE! & 1 & 1 & 0.1 & & & & & & & & & & 0.25 & & 0.25 & 1 & 0 \\
\hline 3.9 & NEAT-o-Race & 1 & 1 & & & & & & 0.1 & & & & & 0.25 & & 0.25 & 0.3 & 1 \\
\hline 1.95 & Human Trials & 0 & 0.5 & 0.1 & & & & & & & & & & 0.25 & 0.25 & 0.25 & 0.6 & 0 \\
\hline 3.25 & Virtual Aquarium & 1 & 0.5 & & & & & & 0.1 & & & & 0.1 & 0.25 & & & 0.3 & 1 \\
\hline 2.85 & Mona Lisa Bookshelf & 1 & 0.5 & & & & & & & & & & 0.1 & 0.25 & & & 0 & 1 \\
\hline 1.5 & Tabletop WarcraftllI & 0 & 0.5 & & & 0.1 & & 0.1 & & & & & & 0.25 & & 0.25 & 0.3 & 0 \\
\hline 2 & PAC LAN & 0 & 1 & & & & & & & & 0.1 & & 0.1 & 0.25 & & 0.25 & 0.3 & 0 \\
\hline 2.6 & BREAKOUT FOR TWO & 0 & 0.5 & 0.1 & & & & & 0.1 & & & & 0.1 & 0.25 & & 0.25 & 0.3 & 1 \\
\hline 1.3 & Swordplay & 0 & 0.5 & & 0.1 & & & & 0.1 & & & & 0.1 & 0.25 & & 0.25 & 0 & 0 \\
\hline 2.9 & Your Way Your Missions & 1 & 1 & & & & & & & & & 0.1 & & 0.25 & & 0.25 & 0.3 & 0 \\
\hline
\end{tabular}

Figure 1. Pervasive Games in TeMPS Framework

How all the games we reviewed are characterized using our TeMP framework and scored is presented in Fig. 1, and information can be got quickly by observing the figure:

- By comparing the final score of each game in the first column, we can see which games are more pervasive according to our scoring criteria (commonly it provides pervasiveness by more means);

- By looking at the scores in one aspect related column, we can pick out games that exemplify that aspect and corresponding techniques (Tabletop WarcraftIII is the only example for Speech aspect for instance);
- By looking at how one game is scored for different aspects in the row, we can see what kind of pervasiveness" the game provides;

- By comparing two games in two lines, we can quickly be aware that which game is more pervasive and what different kinds of pervasiveness they provide individually (Brainball and DARE! are pervasive in quite different way).

There are more interesting facts that can be found in the figure. For instance, although the aspects in perceptibility are independent to each other, few games utilize more than 3 of them. Are the game designers simply not aware of this or feeling difficult to design attractive game play, or blocked by 
other practical issues? Considering the reasons may lead to some guidelines to design a new pervasive game or make an existed game more pervasive. More findings are:

- $\quad$ Speech is seldom used;

- Location is used widely while Route is not;

- Motion is used widely while Balance is seldom used;

- Not like most AR games, BREAKOUT FOR TWO [16] is creative in using Sight;

- $\quad$ STARTS [7] uses a smart way to blend the virtual world and the physical world compared with most AR games, in which, player puts physical objects on the screen- where the virtual objects is presented;

- Object sharing could not be introduced in a large scope because most techniques available either need power supply (blue tooth, wifi) or are limited in functions (RFID only provides static information like what it is). We may need to be ready when these technical obstacles are overcome;

- Most games provide Visual Effect and Auditory Effect at the same time, but there are some exceptions;

- Few games we reviewed provide Force Feedback or Moving Object although it seems effective to bring "pervasiveness".

\section{RELATED WORK}

There is some related work in this area, but we have not found any detailed conceptual frameworks similar to TeMPS. Jegers describes a pervasive gameflow model [38] that focuses on pervasive player enjoyment, which contains some parts that are similar to our conceptual framework. Jegers model is an extension of Sweetser and Wyeth's gameflow model [39] and highlights the areas where pervasive games depart from other games: mobile/placeindependent gameplay, social interaction among players, and integrating physical and virtual worlds. The placeindependence of pervasive games means that games can be played beyond a typical context of PCs or game consoles. Social interaction among players is also a big part of online games, but for some pervasive games it is the core gameplay or game mechanic. Integrating physical and virtual worlds is the really unique feature of pervasive games that you cannot find in ordinary video games. Jegers model includes some of the parts that our model includes, but does not go into detail in each area. Also his model has a different perspective.

Nieuwdorp proposes a model [6] that describes pervasive games according to two perspectives: a technological perspective that focuses on computing technology as a tool to enable the game to come into being, and a cultural perspective that focuses on the game itself and how the game world can be related to the everyday world. There is very little overlap Nieuwdorp's model and our framework.

Walther describes a model [8] describing pervasive games according to four axes: 1) distribution - pervasive games communicate over various networks and are considered to be always online; 2) mobility - pervasive games give new challenges in terms of computing mobility, network mobility, user mobility, and context-aware services;
3) persistence - pervasive games demands total availability all the time; and 4) transmediality - pervasive games uses various kinds of media sent back and forth over the network. However, some conceptual parts and technical parts are mixed. Our framework focuses on the concept level independent to technical implementation, although some game play is heavily restricted by technical part.

Montola suggests in [40] that pervasiveness in games can be defined as those that break the temporal, spatial, or social boundaries of games. This provides a similar way to analyze a pervasive game in principle, however, lacks Perceptibility related discussion compared with our TeMPS framework. Without observation on Perceptibility aspects, a lot of augmented tabletop games, local affective and VR games may be neglected. Besides Perceptibility, the way we look at other perspectives especially the Sociality differs also.

\section{DISCUSSION AND CONCLUSION}

With this article, we have introduced a conceptual framework that includes the important aspects for a game to be pervasive. We also analyzed some typical and popular pervasive games by characterizing them using our framework. By thinking about existing technical constrains with respect to each aspects, we can be sensitive and agile to make use of new techniques in new games. We hope our TeMPS framework could help understanding the pervasive and social aspects of games as well as designing new pervasive games.

As for future work, we do not claim that the suggested set of perspectives or their options/aspects used in this paper is exhaustive, and they can be refined later. For instance, Sociality plays an important role, besides the aspects mentioned here, another important aspect is how the players feel the existence of each other and how they communicate (face-to-face real-time video \&audio? or pure text mails?) [37]. Analysis in this area could be input to extend the TeMPS framework in the future. We also realized that this framework is somewhat empirical and lacks solid theoretical ground which we will put most efforts to improve. Apart from these, the scoring criteria need to be improved to be less subjective.

\section{REFERENCES}

[1] W. Segatto, E. Herzer, C. Mazzotti, J. Bittencourt, and J. Barbosa, "Mobio threat: A mobile game based on the integration of wireless technologies," Comput. Entertain., vol. 6, no. 3, 2008, pp. 1-14.

[2] I. Smith, S. Consolvo, and A. LaMarca, "The Drop: pragmatic problems in the design of a compelling, pervasive game," Computer. Entertainment., vol. 3, no. 3, 2005.

[3] K. Jegers, and M. Wiberg, "Pervasive Gaming in the Everyday World," IEEE Pervasive Computing, vol. 5, no. 1, 2006, pp. 78.

[4] I. LINDT, J. OHLENBURG, U. PANKOKE-BABATZ, and S. GHELLAL, "A report on the crossmedia game epidemic menace," Comput. Entertain., vol. 5, no. 1, 2007, pp. 8.

[5] A.D. Cheok, A. Sreekumar, C. Lei, and L.N. Thang, "Capture the Flag: Mixed-Reality Social Gaming with Smart Phones," IEEE Pervasive Computing, vol. 5, no. 2, 2006, pp. 62-69. 
[6] E. Nieuwdorp, "The pervasive discourse: an analysis," Comput. Entertain., vol. 5, no. 2, 2007, pp. 13.

[7] C. Magerkurth, A.D. Cheok, R.L. Mandryk, and T. Nilsen, "Pervasive games: bringing computer entertainment back to the real world," Comput. Entertain., vol. 3, no. 3, 2005, pp. 4-4.

[8] B.K. Walther, "Atomic actions -- molecular experience: theory of pervasive gaming," Computer. Entertainment, vol. 3, no. 3, 2005.

[9] S. Hjelm, "The making of Brainball," INTERACTIONS-NEW YORK-, 2003, pp. 26-34.

[10] W. Piekarski, and B. Thomas, "ARQuake: the outdoor augmented reality gaming system," 2002.

[11] S.B. Davis, M. Moar, J. Cox, C. Riddoch, K. Cooke, R. Jacobs, M. Watkins, R. Hull, and T. Melamed, "Ere be dragons: an interactive artwork," Book 'Ere be dragons: an interactive artwork, Series 'Ere be dragons: an interactive artwork, ed., Editor ed.^eds., ACM, 2005, pp.

[12] S. Benford, A. Crabtree, M. Flintham, A. Drozd, R. Anastasi, M. Paxton, N. Tandavanitj, M. Adams, and J. Row-Farr, "Can you see me now?," ACM Trans. Comput.-Hum. Interact., vol. 13, no. 1, 2006, pp. $100-133$.

[13] J. Verhaegh, I. Soute, A. Kessels, and P. Markopoulos, "On the design of Camelot, an outdoor game for children," Book On the design of Camelot, an outdoor game for children, Series On the design of Camelot, an outdoor game for children, ed., Editor ed.^eds., ACM, 2006, pp.

[14] M. Chalmers, M. Bell, B. Brown, M. Hall, S. Sherwood, and P. Tennent, "Gaming on the edge: using seams in ubicomp games," Book Gaming on the edge: using seams in ubicomp games, Series Gaming on the edge: using seams in ubicomp games, ed., Editor ed.^eds., ACM, 2005, pp.

[15] M. Brynskov, and M. Ludvigsen, "Mock games: a new genre of pervasive play," Book Mock games: a new genre of pervasive play, Series Mock games: a new genre of pervasive play, ed., Editor ed.^eds., ACM, 2006, pp.

[16] F.F. Mueller, G. Stevens, A. Thorogood, S. O'Brien, and V. Wulf, "Sports over a Distance," Personal Ubiquitous Comput., vol. 11, no. 8, 2007, pp. 633-645.

[17] M. Katzourin, D. Ignatoff, L. Quirk, J.J.L. Jr., and O.C. Jenkins, "Swordplay: Innovating Game Development through VR," IEEE Comput. Graph. Appl., vol. 26, no. 6, 2006, pp. 15-19.

[18] E. TSE, S. GREENBERG, C. SHEN, and C. FORLINES, "Multimodal multiplayer tabletop gaming," Comput. Entertain., vol. 5, no. 2, 2007, pp. 12.

[19] D. Bersak, G. McDarby, N. Augenblick, P. McDarby, D. McDonnell, B. McDonald, and R. Karkun, "Intelligent biofeedback using an immersive competitive environment."

[20] H. Zhang, and B. Hartmann, "Building upon everyday play," 2007.

[21] K. Xu, S.J.D. Prince, A.D. Cheok, Y. Qiu, and K.G. Kumar, "Visual registration for unprepared augmented reality environments," Personal Ubiquitous Comput., vol. 7, no. 5, 2003, pp. 287-298.

[22] L. Chen, and S. Benford, "Your way your missions: from locationbased to route-based pervasive gaming," Book Your way your missions: from location-based to route-based pervasive gaming, Series Your way your missions: from location-based to route-based pervasive gaming, ed., Editor ed.^eds., ACM, 2007, pp.

[23] S. Benford, W. Seager, M. Flintham, R. Anastasi, D. Rowland, J. Humble, D. Stanton, J. Bowers, N. Tandavanitj, and M. Adams, "The error of our ways: the experience of self-reported position in a locationbased game," Lecture notes in computer science, 2004, pp. 70-87.
[24] T. Nakajima, V. Lehdonvirta, E. Tokunaga, M. Ayabe, H. Kimura, and Y. Okuda, "Lifestyle biquitous Gaming: Making Daily Lives More Plesurable," Book Lifestyle Ubiquitous Gaming: Making Daily Lives More Plesurable, Series Lifestyle Ubiquitous Gaming: Making Daily Lives More Plesurable, ed., Editor ed.^eds., IEEE Computer Society, 2007, pp.

[25] A. Cheok, K. Goh, W. Liu, F. Farbiz, S. Fong, S. Teo, Y. Li, and X. Yang, "Human Pacman: a mobile, wide-area entertainment system based on physical, social, and ubiquitous computing," Personal and Ubiquitous Computing, vol. 8, no. 2, 2004, pp. 71-81.

[26] W. Fontijn, and P. Mendels, "StoryToy the interactive storytelling toy."

[27] H. Shwe, and A. Francetic, "Smarter Play for Smart Toys: The Benefits of Technology-Enhanced Play," Zowie Intertainment White Paper, vol. 3208, 1999.

[28] M. Flintham, S. Benford, R. Anastasi, T. Hemmings, A. Crabtree, C. Greenhalgh, N. Tandavanitj, M. Adams, and J. Row-Farr, "Where online meets on the streets: experiences with mobile mixed reality games," ACM New York, NY, USA, pp. 569-576.

[29] P. Lankoski, S. Heli?, J. Nummela, J. Lahti, F. M?yr?, and L. Ermi, "A case study in pervasive game design: the songs of north," ACM New York, NY, USA, pp. 413-416.

[30] J. Peitz, H. Saarenp??, and S. Bj?rk, "Insectopia: exploring pervasive games through technology already pervasively available," ACM New York, NY, USA, pp. 107-114.

[31] O. Rashid, W. Bamford, P. Coulton, R. Edwards, and J. Scheible, "PACLAN: mixed-reality gaming with RFID-enabled mobile phones," Comput. Entertain., vol. 4, no. 4, 2006, pp. 4.

[32] H. Ishii, C. Wisneski, J. Orbanes, B. Chun, and J. Paradiso, "PingPongPlus: design of an athletic-tangible interface for computersupported cooperative play," ACM New York, NY, USA, pp. 394-401.

[33] T. Qui, T. Nguyen, A. Mallawaarachchi, K. Xu, W. Liu, S. Lee, Z. Zhou, S. Teo, H. Teo, and Y. Li, "Magic land: Live 3d human capture mixed reality interactive system," ACM New York, NY, USA, pp. 1142- 1143.

[34] Y. Fujiki, K. Kazakos, C. Puri, P. Buddharaju, I. Pavlidis, and J. Levine, "NEAT-o-Games: blending physical activity and fun in the daily routine," Computers in Entertainment (CIE), vol. 6, no. 2, 2008.

[35] H. Kaufmann, "Construct3D: an augmented reality application for mathematics and geometry education," Book Construct3D: an augmented reality application for mathematics and geometry education, Series Construct3D: an augmented reality application for mathematics and geometry education, ed., Editor ed.^eds., ACM, 2002, pp.

[36] J. Anstey, S. Bay-Cheng, D. Pape, and S.C. Shapiro, "Human trials: an experiment in intermedia performance," Comput. Entertain., vol. 5, no. 3, 2007, pp. 4.

[37] Y.A.W.D. Kort, and W.A. Ijsselsteijn, "People, places, and play: player experience in a socio-spatial context," Comput. Entertain., vol. 6 , no. 2, 2008, pp. 1-11

[38] K. Jegers, "Pervasive game flow: understanding player enjoyment in pervasive gaming," Computers in Entertainment (CIE), vol. 5, no. 1, 2007.

[39] P. Sweetser, and P. Wyeth, "GameFlow: a model for evaluating player enjoyment in games," Computers in Entertainment (CIE), vol. 3, no. 3, 2005, pp. 3-3.

[40] M. Montola, "Exploring the edge of the magic circle: Defining pervasive games." In Proceedings of DAC 2005 Conference (IT University of Copenhagen, Denmark) 